\title{
Analysis of Economic Factors Attracting FDI in West China since Reform and Opening-up
}

\author{
Wenfei Lan \\ Graduate School of International Trade \\ Southwestern University of Finance and Economics \\ Chengdu 610074, China \\ E-mail: lanwf1984@yahoo.com.cn \\ Qie Yin \\ College of International Business \\ Southwestern University of Finance and Economics \\ Chengdu 610074, China \\ E-mail: yinq1985@yahoo.com.cn
}

\begin{abstract}
Since China performed the policy of reform and opening-up 30 years ago, foreign direct investment (FDI) has exerted important function in the quick development of economy, but the location factors of West China and East China are very different, and their attractions to FDI are not same. According to the location theory of FDI, in this article, taking the city of Chengdu as the example, we utilized the method of co-integration to empirically analyze the economic factors attracting FDI in West China in past 30 years since reform and opening-up. And the analysis results indicate that quicker economic growth, higher opening degree and investment in fixed assets are important economic factors to attract foreign investments for the city of Chengdu.
\end{abstract}

Keywords: Foreign direct investment (FDI), Location theory, Co-integration, Error correction, Economic factors

\section{Introduction}

Under the background of the development of the west regions, the situation of attracting investments in West China is still just passable. To analyze the economic factors influencing the FDI in west regions can help us find the solution of the problem and promote the investment attraction in west regions. According to the statistics of Sichuan, Chengdu introduced 0.76 billion dollars in 2006, which increased $38.3 \%$ than the year of 2005 . Though the investments attraction is increasing, but the increase degree is quite less than the east regions. In this article, taking the city of Chengdu as the example, based on the data of 17 years from 1990 to 2006, we analyze the economic factors influencing FDI in west regions to put forward feasible advices to attract FDI for west regions.

In this article, we adopt the co-integration method in the time sequence analysis, which doesn't require the time sequence of economic phenomena is stable, and can compensate the deficiency of same researches which adopt the multiple-regression analysis method and make the research results more reliable.

\section{Theoretical base and model}

\subsection{Location theory of FDI}

John Harry Dunning divided the location factors influencing FDI into four sorts including the market factor, the trade barrier, the cost factor and the investment climate. J.R.L. Howells (1984) divided the determinant factors of investment location selection into non-system factors and system factors, where, non-system factors include economic factors such as market scale, labor cost, basic establishment and cluster economic. The "World Investment Report of 1998" pointed out in the determinant factors of host country for FDI, the influence of the economic factors was very important under the premise of free policy, and these factors included market scale, cheap skilled labor force and material basic establishments. 
Starting from the acquisition of data and actual economic influencing factors, this article thought the economic development situation, labor cost, trade barrier, material basic establishment and FDI accumulation are main economic factors, and based on that, this article would further analyze the concrete situation of Chengdu.

\subsection{Model and data source}

\subsubsection{Model}

Combining with the FDI location selection theory and other scholars' researches and considering the acquisition of data, in this article, we select the actual FDI utilization amount of Chengdu as the attributive variable, and select the economic factors influencing FDI as the independent variables which are divided into five sorts, and each sort is denoted by corresponding statistical index.

(1) Economic development situation (GDP)

GDP is used to reflect the total economic development situation of Chengdu, and the total development level is higher, that indicates enterprises face more chances. At the same time, quicker GDP increase speed will attract more enterprise investments.

(2) Labor cost (WAGE)

Employee yearly average wage of Chengdu is used to reflect the labor cost. And cheap labor forces will more FDI.

(3) Imports and exports amount (OPEN)

The imports and exports amount of Chengdu can reflect the trade barrier, and more amounts of imports and exports indicate the opening degree of the city. In the region with higher opening degree, the basic establishment, laws and regulations, and culture and information will be in higher opening degree, so it will reduce the information cost and trade cost, and attract FDI.

(4) Capital formation (INV)

The yearly fixed investment amount of Chengdu can reflect the construction of basic establishments and the information and guarantee of long-term economic development. For FDI, the increase of fixed investment is represented as the improvement of the investment environment in the investment region, which is propitious to attract FDI.

(5) FDI accumulation

The accumulated FDI amount of past two years of Chengdu is used to reflect the FDI accumulation and the cluster effect of the economy, and more FDI accumulation indicates better investment environment and will attract more FDI.

\subsubsection{Data source}

The data are from the data of 17 years from 1990 to 2006 in "Sichuan Yearbook of Statistics". The unit of FDI and OPEN are modified as ten thousand Yuan according the exchange rate of "Chinese Statistics Yearbook". The price index is computed by the $1900=100$.

To eliminate the heteroscedasticity of the time sequence, in this article, we implement logarithm processing to various variables including LFDI, LGDP, LWAGE, LOPEN, LINV and LFDIS. The data processing in the article is completed by the software EVIEW3.0.

\section{Model test}

\subsection{Causality test}

\subsubsection{Analysis of variable correlation}

To test whether the selected variables possess correlation relationship, we will make following correlation tests.

From Table 2, though high correlations exist among variables, but that doesn't mean the causality exist among variables, so we should implement the test of causality.

\subsubsection{Causality test}

Through the granger causality tests to LFDI, LGDP, LWAGE, LOPEN, LINV and LFDIS, we can obtain the test results (seen in Table 3), and the test results show the $\mathrm{F}$ statistics and the value of $\mathrm{P}$, and indicate that under the significant level of $5 \%$, when the lagged term is 4, FDI and WAGE are reasons each other, and GDP, INV and OPEN are the reason of FID, and FDI is the reason of FDIS, but FDIS is not the reason of FDI. That indicates the change of wage level of Chengdu will influence the inflow of FDI. At the same time, the inflow of FDI will certainly promote the accumulation of FDI, but the accumulation of FDI would not attract the inflow of FDI, because the FDI accumulation of Chengdu doesn't exert corresponding cluster effect.

Therefore, according to the Granger causality test, we select LGDP, LWAGE, LOPEN and LINV as explanation variables. 


\subsection{Stability test of sequence}

ADF test is used to implement stability test to variables including LFDI, LGDP, LWAGE, LOPEN and LINV. If the $\mathrm{ADF}$ is bigger than the critical value, so the time sequence data are unstable, and the test results are seen in Figure 4, and we can see that all sequences are first-order monotonously.

\subsection{Long-term balance analysis}

According to above tests, we adopt EG method to implement co-integration test. First, we regress to LFDI, LGDP, LWAGE, LOPEN and LINV, and the regression results are

LFDI $=-15.81627+1.847449$ LGDP- 4.829677LWAGE +0.993140 LOPEN +1.843420 LINV

$\mathrm{T}=(1.746491)(-3.437969)(1.813246)(2.529642)$

R-squared $=0.940829$

Adjusted R-squared $=0.921105$

F-statistic $=47.70044$

From above regression results, we can see that the fitting effect of the model is higher, and the results testing the stability of the residual sequence of regression results are seen in Table 5. From Table 5, the residual sequence is stable, which indicates the co-integration relation exists in attributive variables and independent variables and the relation is exclusive.

From the regression results, the positive influences of GDP, WAGE, OPEN and INV to FID are obvious, but the WAGE presents negative influence to the inflow of FDI. The positive influence of economic scale is the largest one, and every increasing one percent will make FDI increase 1.847449 percents, and the influence of fixed assets to FDI is large, and when the fixed assets increase one percent, it will promote the FDI to increase 1.84342 percents. And when the amount of imports and exports increases one percents, the inflow of FDI will increase 0.99314 percents. When the labor wage increases one percent, the flux of FDI will decrease 4.829677 percents, and the increase of wage will seriously baffle the inflow of FDI.

\subsection{Model of error correction}

Above analysis only aims at the long-term balance, and we will consider the short-term dynamic relation among variables by the model of ECM. Through former evaluation, we can obtain the residual sequence $\mathrm{E}(\mathrm{t})$, and we establish the error correction model taking the residual $\mathrm{E}(\mathrm{t}-1)$ of lagged term as the non-balance error, i.e.

$\Delta \mathrm{LFDI}=-0.600870+1.254550 \Delta \mathrm{\Delta}$ GDP $+1.679108 \boldsymbol{\Delta} \mathrm{LWAGE}+1.721345 \boldsymbol{\Delta} \mathrm{LINV}+0.196414 \boldsymbol{\Delta}$ LOPEN-0.807916E $(\mathrm{t}-1)$

$\mathrm{T}=(0.755879)(0.692110)(2.314374)(0.601369)(-3.509911)$

R-squared $=0.845580$

Adjusted R-squared $=0.768370$

F-statistic $=10.95168$

As a whole, the fitting effect is good, and from the model, we can also see that there is one item of the symbol of short-term variable which differs with the symbol of the long-term balance relation, and the influencing degree sequences of various variables are different with the long-term variables. In the long term, the labor wage baffles the FDI, but in the short term, the labor wage promotes the FDI, and the reason may be that in the short term, the investors don't consider this factor, or they more emphasize the quality of the talents and they hope to introduce the talents with high quality in the initial stages of the investment, so the labor wage will be higher. That point also is embodied in the Granger causality test, and the inflow of FDI promotes the enhancement of the labor wage. As viewed from the long term, the labor wage baffles the FDI. But in the short term, the most influencing factor to the inflow of FDI is the amount of fixed assets investment, which indicates that in the short term, the main factors attracting FDI of Chengdu are related with the acquisition of information and the investment environment.

\section{Conclusions and policy advices}

As viewed from the long term, the economic factors that Chengdu attracts the inflow of FDI include quick economic growth, higher opening degree, higher fixed assets investment and cheap labor cost. But in the short term, the influence of the labor cost is different, and it promotes the inflow of FDI, because the in the initial stage of the inflow of FDI, investors would employ the labor force with high costs, but in the long term, the cheap labor force occupies the advantage. In the short term, the labor wage doesn't baffle the FDI because the foreign investors would pay higher costs when they want to attract talents in the initial stage, so in the short term, both sides present mutually stimulative function (the result of Granger test also proved that).

Whether in the long term or in the short term, the FDI accumulation of Chengdu doesn't promote the inflow of FDI, and 
the reason may be the amount of FDI accumulation has not achieve certain scale, and the cluster effect has not been formed.

In the long-term balance, the economic growth is the most important influencing factor, which indicates the inflow of FDI in Chengdu roots in the stable economic development under the policy of the development of the west regions of China. So in the instruction of the policy, the stable and healthy development of economy is the important economic factor to attract FDI for west regions.

In the short-term fluctuation model, the most significant factor influencing the inflow of FDI is the amount of fixed assets investment, which indicates the good investment environment is the key to attract FDI, and the good investment environment mainly includes good basic establishments, perfect traffic network and information network.

Therefore, we put forward following advices:

(1) Perfecting the construction of basic establishments to offer the hardware support of the inflow of FDI. From the test results, whether in the long term or in the short term, the construction of basic establishments is very important for the inflow of FDI. So the public departments should strengthen the construction of basic establishments and build good investment environment, and increase the investors' confidences to the development of the economy.

(2) Maintaining higher economic growth speed. Quicker economic growth is the main reason for the inflow of FDI in the long term, and it reflects the economic scale and the development foreground. And investors all emphasize the macro economic development status of the region.

(3) Paying attention to foster talents and increase the education payout. In the short term, FDI emphasizes the talents' skills, but in the long term, it emphasizes the investment of labor cost. Therefore, the west regions should strengthen the force to cultivate talents, and under same skill standard, lower labor cost will more attract the investors.

(4) Reducing the trade barriers and offering stable system environment. The opening degree of the economy is mainly limited by the policy, so the policy of attracting investments and the stable system environment will improve the inflow of FDI, and investors will produce higher anticipated return and increase the investments.

\section{References}

Bruno Solnik. (2004). International Investment (4th Edition). Beijing: China Renmin University Press.

Gao, Tiemei. (2006). Measurement Economic Analysis Method and Modeling: EVIEWS Application and Examples. Beijing: Tsinghua University Press.

Li, Lixin \& Jin, Rungui. (2002). A Comparative Analysis on Location Factors of Different Groups of FDI in China. China Soft Science, No. 7.

Pan, Zhen. (2005). Location Decision of FDI: Its Generalization, Heterogeneity and Effectiveness--An Empirical Investigation of 3570 Jiangsu Foreign-Invested Enterprises. China Soft Science, No. 7.

Qi, Xiaohua. (2004). Chinese Scholars' Comparative Analysis on Theory and Model of FDI. World Economy Study, No. 5.

Wang, Rongcan. (2004). Change Tendency of International Direct Investment and the Policy Adjustment that China Utilizes Foreign Investments. Asia-Pacific Economic Review, No. 3.

Zhao, Guoqing. (2004). Study on the Absorption Ability of Chinese Western International Direct Investment. Beijing: China Social Sciences Press.

Table 1. Influencing direction of anticipated variable

\begin{tabular}{|c|c|}
\hline Variable & Anticipated influencing direction \\
\hline GDP & + \\
\hline WAGE & - \\
\hline OPEN & + \\
\hline INV & + \\
\hline FDIS & + \\
\hline
\end{tabular}


Table 2. Correlation test of LFDI, LGDP, LWAGE, LOPEN, LINV and LFDIS

\begin{tabular}{|c|c|c|c|c|c|c|}
\hline & LFDI & LFDIS & LGDP & LINV & LOPEN & LWAGE \\
\hline LFDI & 1 & 0.93829579 & 0.917200165 & 0.93659585 & 0.90205018 & 0.886192939 \\
\hline
\end{tabular}

Table 3. Results of Granger causality test

\begin{tabular}{|c|c|c|c|}
\hline \multicolumn{4}{|c|}{ Pairwise Granger Causality Tests } \\
\hline \multicolumn{4}{|c|}{ Date: $05 / 06 / 08 \quad$ Time: $22: 49$} \\
\hline \multicolumn{4}{|c|}{ Sample: 19902006} \\
\hline \multicolumn{2}{|l|}{ Lags: 4} & & \\
\hline Null Hypothesis: & Obs & F-Statistic & Probability \\
\hline LFDIS does not Granger Cause LFDI & 13 & 2.16108 & 0.23691 \\
\hline \multicolumn{2}{|l|}{ LFDI does not Granger Cause LFDIS } & 269.903 & $4.1 \mathrm{E}-05$ \\
\hline LGDP does not Granger Cause LFDI & 13 & 6.88472 & 0.04418 \\
\hline \multicolumn{2}{|l|}{ LFDI does not Granger Cause LGDP } & 2.38123 & 0.21067 \\
\hline LINV does not Granger Cause LFDI & 13 & 12.5042 & 0.01564 \\
\hline \multicolumn{2}{|l|}{ LFDI does not Granger Cause LINV } & 1.16404 & 0.44326 \\
\hline LOPEN does not Granger Cause LFDI & 13 & 11.5828 & 0.01794 \\
\hline \multicolumn{2}{|c|}{ LFDI does not Granger Cause LOPEN } & 1.13547 & 0.45249 \\
\hline LWAGE does not Granger Cause LFDI & 13 & 18.7675 & 0.00742 \\
\hline \multicolumn{2}{|c|}{ LFDI does not Granger Cause LWAGE } & 8.21861 & 0.03275 \\
\hline
\end{tabular}

Table 4. Results of ADF test

\begin{tabular}{|c|c|c|c|}
\hline Variable & ADF test & Critical value (5\%) & Determinant conclusion \\
\hline LFDI & -1.128325 & -3.1222 & Unstable \\
\hline $\mathbf{\Delta}$ LFDI & -7.992439 & -3.1483 & Unstable \\
\hline LGDP & -1.667461 & -3.1222 & Stable \\
\hline $\boldsymbol{\Delta}$ LGDP & -4.974729 & -3.1483 & Unstable \\
\hline LWAGE & -2.088548 & -3.1222 & Stable \\
\hline$\Delta$ LWAGE & -5.438888 & -3.1483 & Stable \\
\hline LINV & 2.731951 & -3.1222 & Unstable \\
\hline L LINV & -6.039470 & -3.1483 & Stable \\
\hline
\end{tabular}

Table 5. Stability test of residual sequence

\begin{tabular}{|c|c|c|c|}
\hline ADF Test Statistic & -4.001997 & $1 \% \quad$ Critical Value* & -4.0113 \\
\hline & & $5 \% \quad$ Critical Value & -3.1003 \\
\hline & & $10 \%$ Critical Value & -2.6927 \\
\hline
\end{tabular}

